\title{
Adult Shell-size Regulation in Conispirally-coiled Shells: Evidence for a Widespread Negative Covariance between Whorls Growth-rate and the Final Number of Whorls in Land Snails
}

\author{
Jean Béguinot ${ }^{1 *}$ \\ 1 Université de Bourgogne, 6 Boulevard Gabriel, 21000 Dijon, France.
}

Author's contribution

The sole author designed, analysed, interpreted and prepared the manuscript.

Article Information

DOI: 10.9734/ARRB/2021/v36i1030439

Editor(s):

(1) Dr. Gonzalo Emiliano Aranda Abreu, Veracruzana University, Mexico.

Reviewers:

(1) Anil Deka, College of Veterinary Science, India.

(2) Anuradha Bhardwaj, ICAR-National Research Centre on Equines, India.

(3) Ahmad Muhtadi, University of Sumatera Utara, Indonesia. Complete Peer review History: https://www.sdiarticle4.com/review-history/75437

Original Research Article

Received 09 August 2021

Accepted 18 October 2021

Published 22 October 2021

\begin{abstract}
As shown, in particular, by the late S.J. Gould, the involvement of a regulation process, aiming at limiting the range of intraspecific variations in adult shell size, in those land snail species with determinate growth, can be indirectly, but conveniently, diagnosed by highlighting a negative covariance between the whorls growth-rate and the whorls number reached at adulthood. However, up to now, such kind of regulation had only been demonstrated in very few cases among land snails and shelled Gastropods in general. Accordingly, quite more extensive checking is required, across both the taxonomic spectrum and the geometrical range of shell profiles. The present report is a very preliminary contribution addressing these issues, which have been neglected for too long. Considering a still limited number of eight species, yet largely encompassing both taxonomic range and shell profiles, it is shown that strong negative covariances between whorls growth-rate and whorls number are systematically highlighted, thereby supporting the involvement of an efficient regulation process of adult shell size and shape in each eight species. Moreover, the degree of regulation of the adult shell size has been quantified and this regulation proves being remarkably effective as a whole, while yet remaining highly species-specific, with very significant disparities among species - and this, somewhat surprisingly, being quite irrespective of the type of geometrical profiles of shells, among the studied species.
\end{abstract}


Keywords: Gastropod shell morphometry; conispiral model; intraspecific variability.

\section{INTRODUCTION}

Many animals exhibit determinate-growth, that is the adult body size of individuals belonging to a given species is usually constrained to remain within a more or less narrow, definite range of values, proper to the species. Many species of conispirally-coiled shelled Gastropods, in particular land snails, show determinate growth. Although shell volume not necessarily strictly identifies to soft body volume in land snails, the former usually tightly reflects the latter. And in particular, the overall shell morphometry (either shell height or shell diameter) exhibits a determinate growth as well, directly answering the determinate growth of its dweller.

In typically conispirally coiled shells, the overall shell size depends on the combination of three main factors: (i) the size of the first whorl, (ii) the expanding ratio of the section of the (exponentially growing) successive whorls and (iii) the achieved number ' $n_{a}$ ' of whorls at adult stage ("fully blown" shell) [1].

One may conveniently combine the two first contributions in a "shell growth parameter" here labelled as ' $\mathrm{Y}$ ' (see Appendix for its definition and computation method). So that a given overall shell size may be achieved by various negatively covariant - combinations of $n_{a}$ and $y$ values. What GOODFRIEND [1] comments in more literal terms as "a given size may be achieved by few whorls which expand rapidly or by numerous whorls that expand slowly". GouLD [2] said substantially the same when pointing out that "shell may reach larger size either by growing more whorls or by growing larger whorls".

This implies, in turn, that a negative covariance is expected to occur between $n_{a}$ and $\mathrm{Y}$ if a regulation process is involved. The latter aiming at constraining the overall shell-size to remain within a limited - species specific - range. Accordingly, actually recording a negative covariance between $n_{a}$ and $y$ would thus support the involvement of such a regulation process. And would thus aptly serve as a diagnostic criterium for this regulating process, as GOULD had shown for the land snail genus Cerion [2-5].

It does not appear, however, that the issue has been addressed much further, following the seminal investigations of GOULD and coworkers (but yet see punctual reports [6-8]). And this neglect despite the interest that there would be to verify that, beyond the case of Cerion, the tendency to such negative covariances would, in fact, be quite more widespread among land snail species, as can be expected.

The present work aims at contributing to such desirable further investigations, by considering eight land snail species, more or less commonly encountered in France.

\section{MATERIALS AND METHODS}

Eight populations were sampled for the eight following species, among which three have globular shells, one has discoidal shell and four have more or less elongate shells:

* Cepaea nemoralis (Linneaus 1758) : 103 sampled adult individuals, located at Saint Vallerin (Saône \& Loire department, south Burgundy);

* Cornu aspersum (O.F. Müller 1774) : 33 sampled adult individuals, located at Salins-lesBains (Jura department, Franche-Comté);

* Monacha cartusiana (O.F. Müller 1774) : 115 sampled adult individuals, located at Saint Vallerin (Saône \& Loire department, south Burgundy);

* Helicodonta obvoluta (O.F. Müller 1774) : 83 sampled adult individuals, located at Blois-surSeille (Jura department, Franche-Comté);

* Pomatias elegans (O.F. Müller 1774) : 110 sampled adult individuals, located at Saint Vallerin (Saône \& Loire department, south Burgundy);

* Chondrula tridens (O.F. Müller 1774) : 51 sampled adult individuals, located at Germagny (Saône \& Loire department, south Burgundy);

* Ena montana (Draparnaud 1801) : 28 sampled adult individuals, located at Val-Suzon (Côte d'Or department, central Burgundy);

* Zebrina detrita (O.F. Müller 1774) : 43 sampled adult individuals, located at Le Parrotier (Vaucluse department, Provence).

For each examined shell, both the number of whorls $n_{a}$ and the shell size (diameter $D_{a}$ or height $\mathrm{H}_{\mathrm{a}}$ ) were measured: 
- the shell size by using a numeric calliper (to the precision of $1 / 10 \mathrm{~mm}$ );

- the number of whorls by careful examination of the shell, examined from the apex, according to the procedure prescribed by KERNEY \& CAMERON [9], using a stereo-microscope at moderate magnification, a procedure which typically allows reaching a precision at the level of 1/10 whorl revolution. Subsequently, the differential growth parameter ' $\mathrm{Y}$ ' is measured according to the procedure originally described in BÉGUINOT $[6,7]$ and briefly recalled below, in the Appendix.

Besides the number of whorls $n_{a}$ and the overall shell size at adulthood (i.e. shell diameter $D_{a}$ for globular or discoidal shells or shell height $\mathrm{H}_{\mathrm{a}}$ for elongate shells), the growth parameter $\mathrm{y}$ (which, together with $n_{a}$, determine the adult shell size) is thus conveniently and easily made available for each individual shell in the population under study.

As regards the estimations of the statistical significance of the reported results, the Student $t$ test was used to characterize both: the degree of significance of the reported negative correlation between $n_{a}$ and $y$ and

- the degree of significance of the reported reduction of the slope of the dependence of the shell size $\left(\mathrm{D}_{\mathrm{a}}\right.$ or $\left.\mathrm{H}_{\mathrm{a}}\right)$ upon the number of whorls $\mathrm{n}_{\mathrm{a}}$, as compared to what this slope would be in the absence of regulation. Reduction which thereby highlights the degree of efficiency of the regulation of adult shell size

\section{RESULTS}

For each of the eight studied species, the series of Figs. 1 to 16 provide:

- on the left, the regression of the number of whorls at adult stage $n_{a}$ against the differential growth parameter $\mathrm{\gamma}$, computed as described in Appendix. Allowing thus to check for the occurrence of a statistically significant negative covariance between both parameters $n_{a}$ and $Y-$ as such symptomatic of the involvement of a regulation process limiting the range of variation of the overall shell size at adulthood;
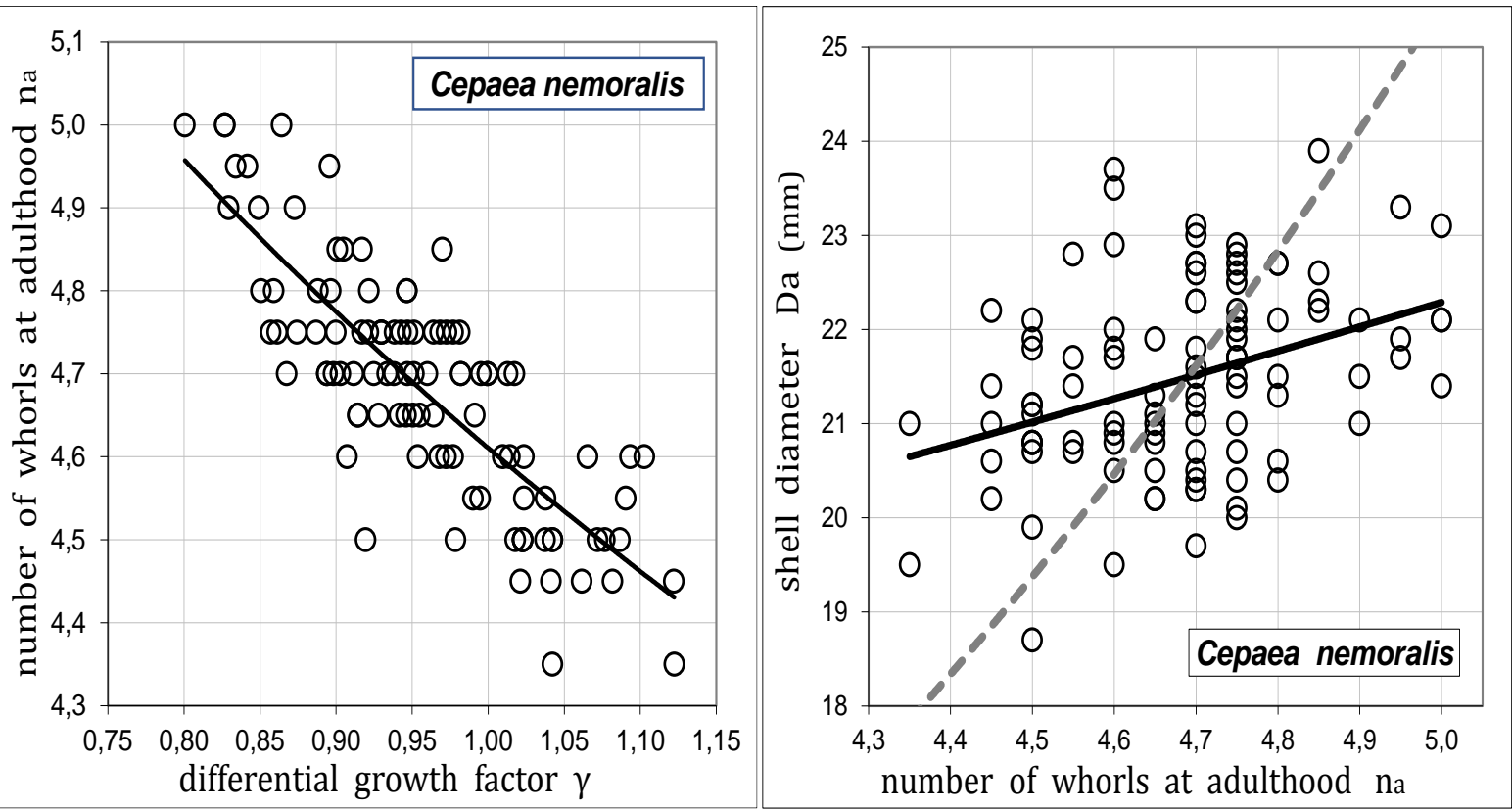

Figs. $1 \& 2$. Shell size regulation in a population of 103 individuals of the land snail Cepaea nemoralis. Left: negative covariance between the number of whorls at adulthood $\mathrm{n}_{\mathrm{a}}$ and the differential growth factor $y(r=-0.82, p<0.0001)$, symptomatic of the resulting regulation of shell size. Right: shell diameter plotted against the number of whorls $\mathrm{n}_{\mathrm{a}}$; the slope of the regression (solid line) turns out to be 4.73 times lower than it would be if no regulation of the shell size had actually occurred (dashed line): $t=14.5$, d.d.I $=101, p<0.0001$. 

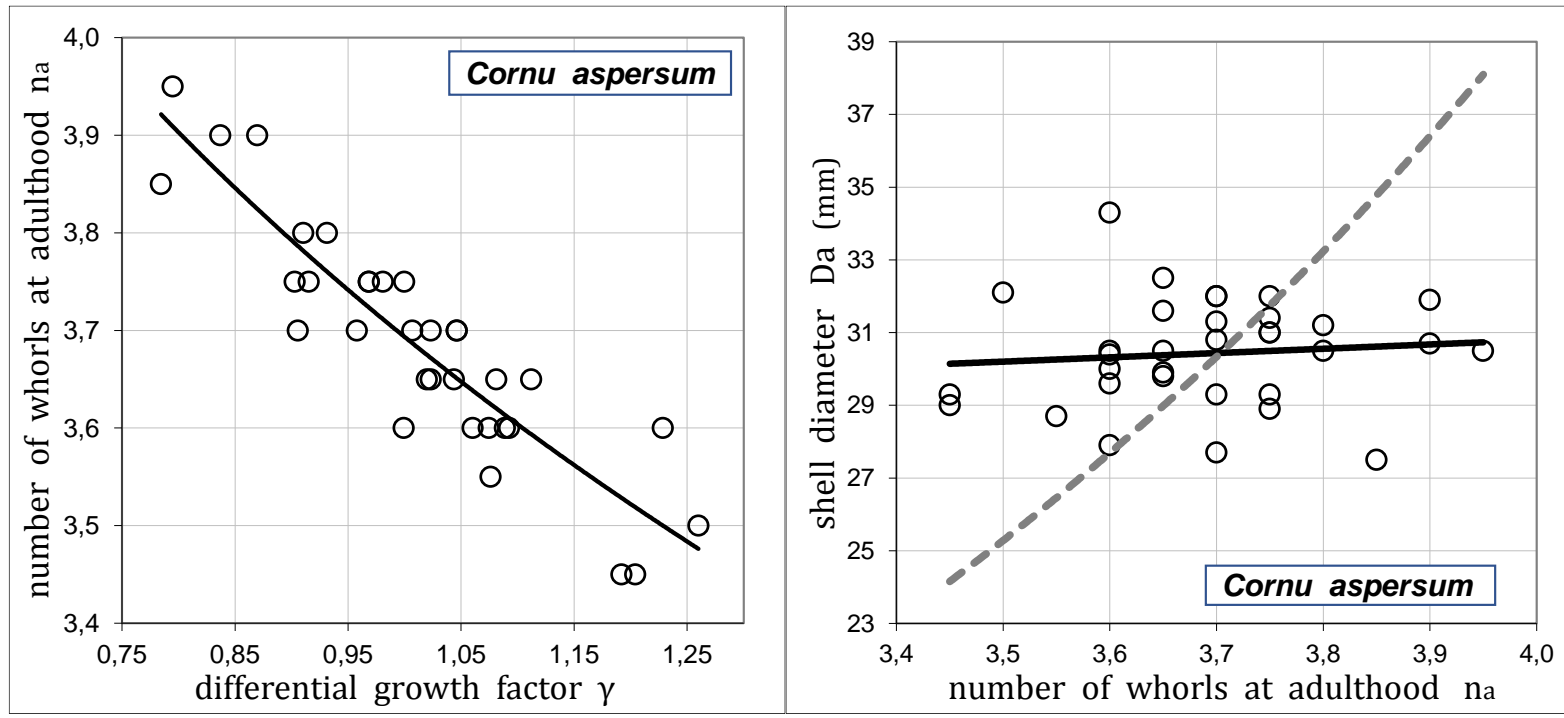

Figs. 3 \& 4 . Shell size regulation in a population of 33 individuals of the land snail Cornu aspersum. Left: negative covariance between the number of whorls at adulthood $\mathrm{n}_{\mathrm{a}}$ and the differential growth factor $Y(r=-0.90, p<0.0001)$, symptomatic of the resulting regulation of shell size. Right: shell diameter plotted against the number of whorls $\mathrm{n}_{\mathrm{a}}$; the slope of the regression (solid line) turns out to be $\mathbf{2 4 . 3}$ times lower than it would be if no regulation of the shell size had actually occurred (dashed line): $t=11.8$, d.d.I $=31, p<0.0001$.
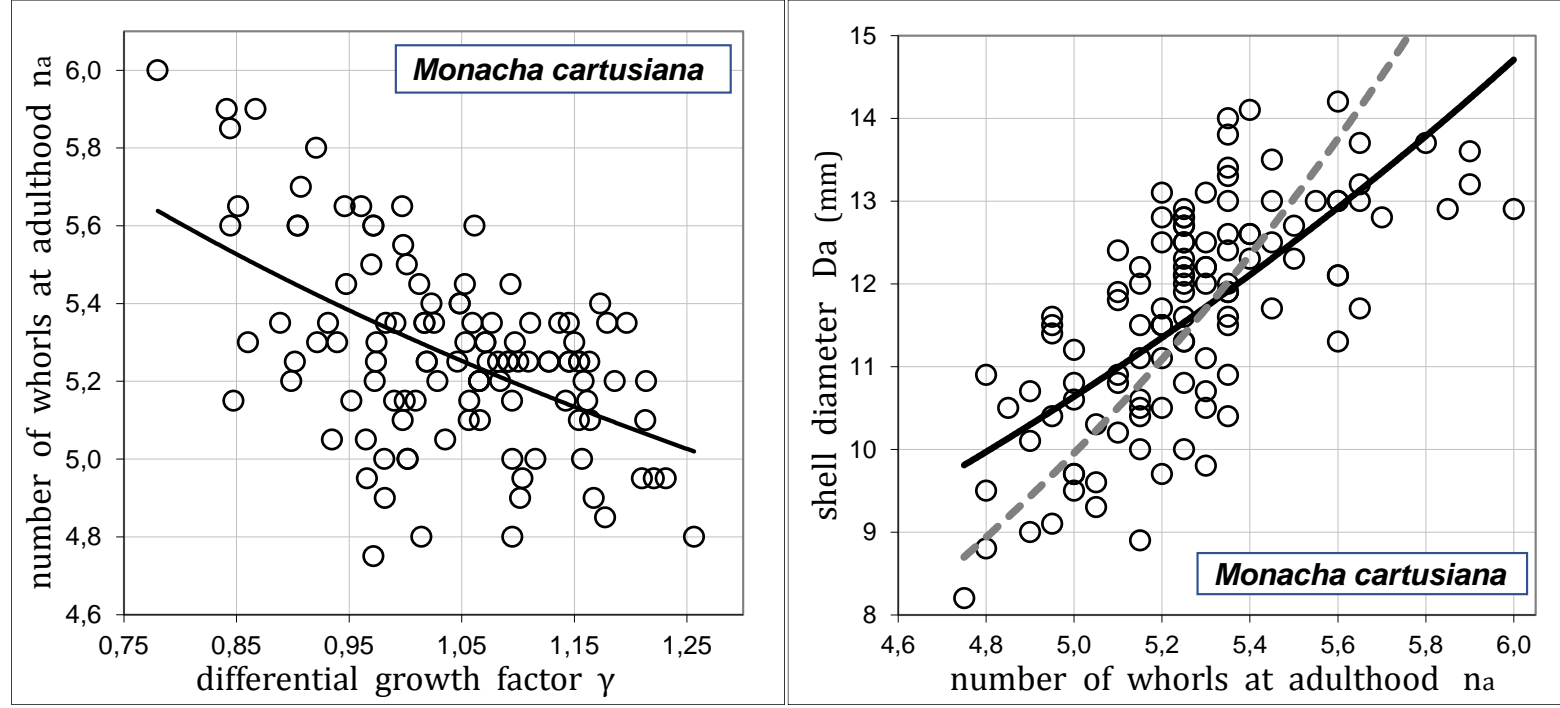

Figs. $5 \& 6$. Shell size regulation in a population of 115 individuals of the land snail Monacha cartusiana. Left: negative covariance between the number of whorls at adulthood $\mathrm{n}_{\mathrm{a}}$ and the differential growth factor $y(r=-0.53, p<0.0001)$, symptomatic of the resulting regulation of shell size. Right: shell diameter plotted against the number of whorls $\mathrm{n}_{\mathrm{a}}$; the slope of the regression (solid line) turns out to be $\mathbf{1 . 7 5}$ times lower than it would be if no regulation of the shell size had actually occurred (dashed line): $t=7.59$, d.d.I $=113, p<0.0001$.

- on the right, the overall shell size $\left(\mathrm{D}_{\mathrm{a}}\right.$ or $\left.\mathrm{H}_{\mathrm{a}}\right)$ plotted against the number of whorls at adult stage $n_{a}$. For comparison, is also provided in the same Figure, the variation of the overall shell size with $n_{a}$, computed for a single individual of the species (dashed grey line), which is representative of the trend of variations of shell sizes with $\mathrm{n}_{\mathrm{a}}$ if no regulation had taken place. Accordingly, the highlighted reduction of the slope of the dependence of shell size (solid line) 
- as compared to what would be this slope in the absence of regulation (dashed grey line) - thus allows to appreciate the degree of efficiency of the process actually involved in the regulation of adult shell size. Being understood that an ideally perfect regulation would have led to a perfect invariance of the overall shell size with the number of whorls at adult stage.
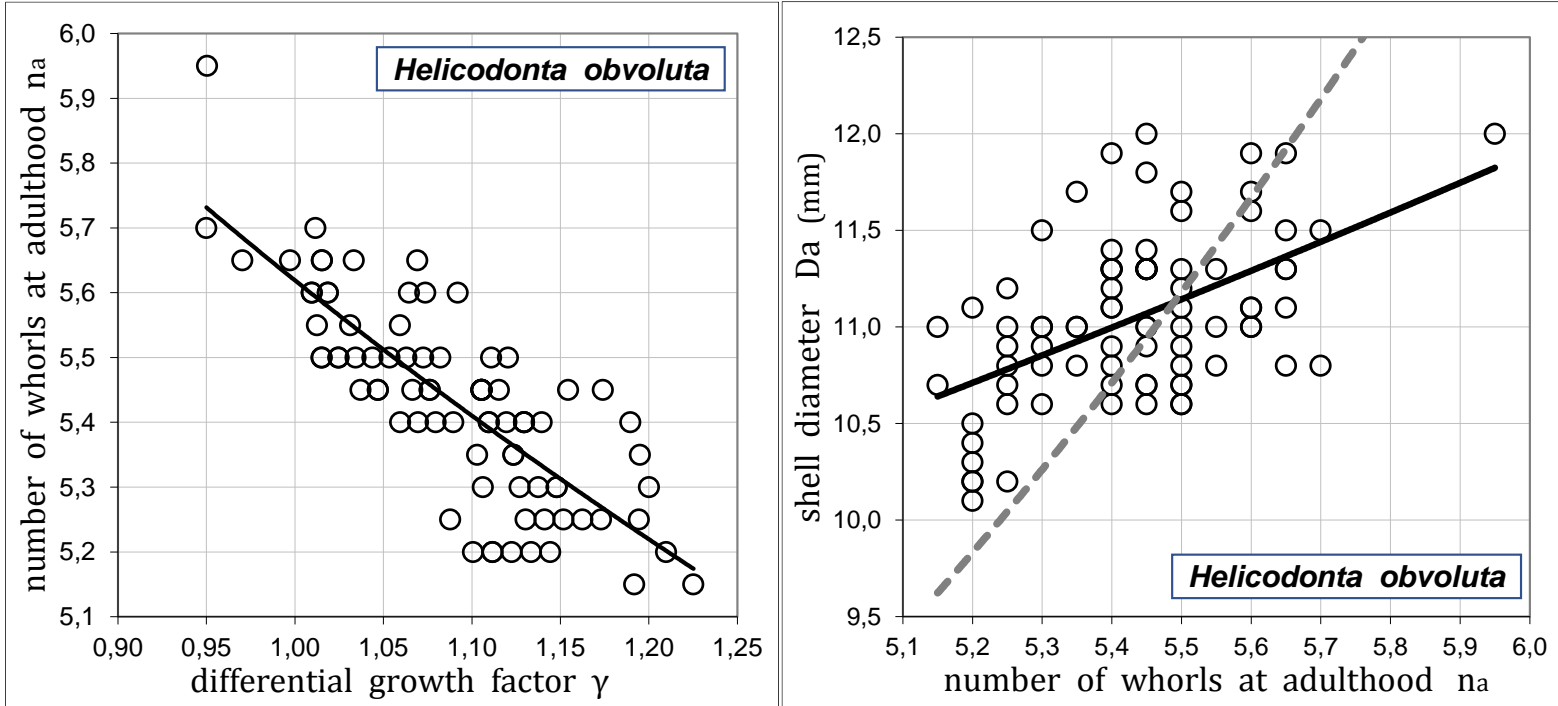

Figs. $7 \&$ 8. Shell size regulation in a population of 83 individuals of the land snail Helicodonta obvoluta. Left: negative covariance between the number of whorls at adulthood $\mathrm{n}_{\mathrm{a}}$ and the differential growth factor $y(r=-0.81, p<0.0001)$, symptomatic of the resulting regulation of shell size. Right: shell diameter plotted against the number of whorls $\mathrm{n}_{\mathrm{a}}$; the slope of the regression (solid line) turns out to be 3.24 times lower than it would be if no regulation of the shell size had actually occurred (dashed line): $t=12.1$, d.d.I $=81, p<0.0001$.
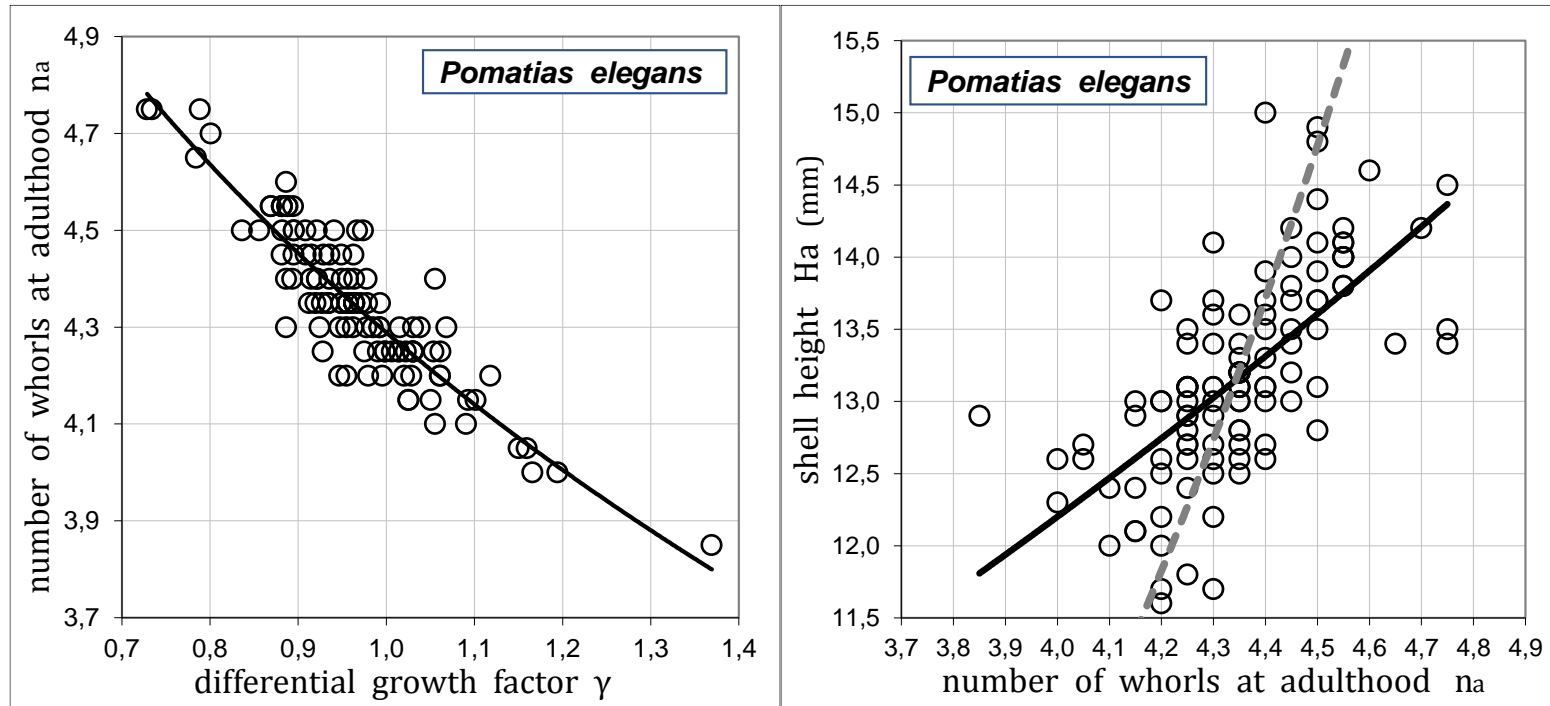

Figs. 9 \& 10. Shell size regulation in a population of 110 individuals of the land snail Pomatias elegans. Left: negative covariance between the number of whorls at adulthood $n_{a}$ and the differential growth factor $Y(r=-0.90, p<0.0001)$, symptomatic of the resulting regulation of shell size. Right: shell height plotted against the number of whorls $\mathrm{n}_{\mathrm{a}}$; the slope of the regression (solid line) turns out to be $\mathbf{3 . 4 3}$ times lower than it would be if no regulation of the shell size had actually occurred (dashed line): $t=22.1$, d.d.I $=108, p<0.0001$. 

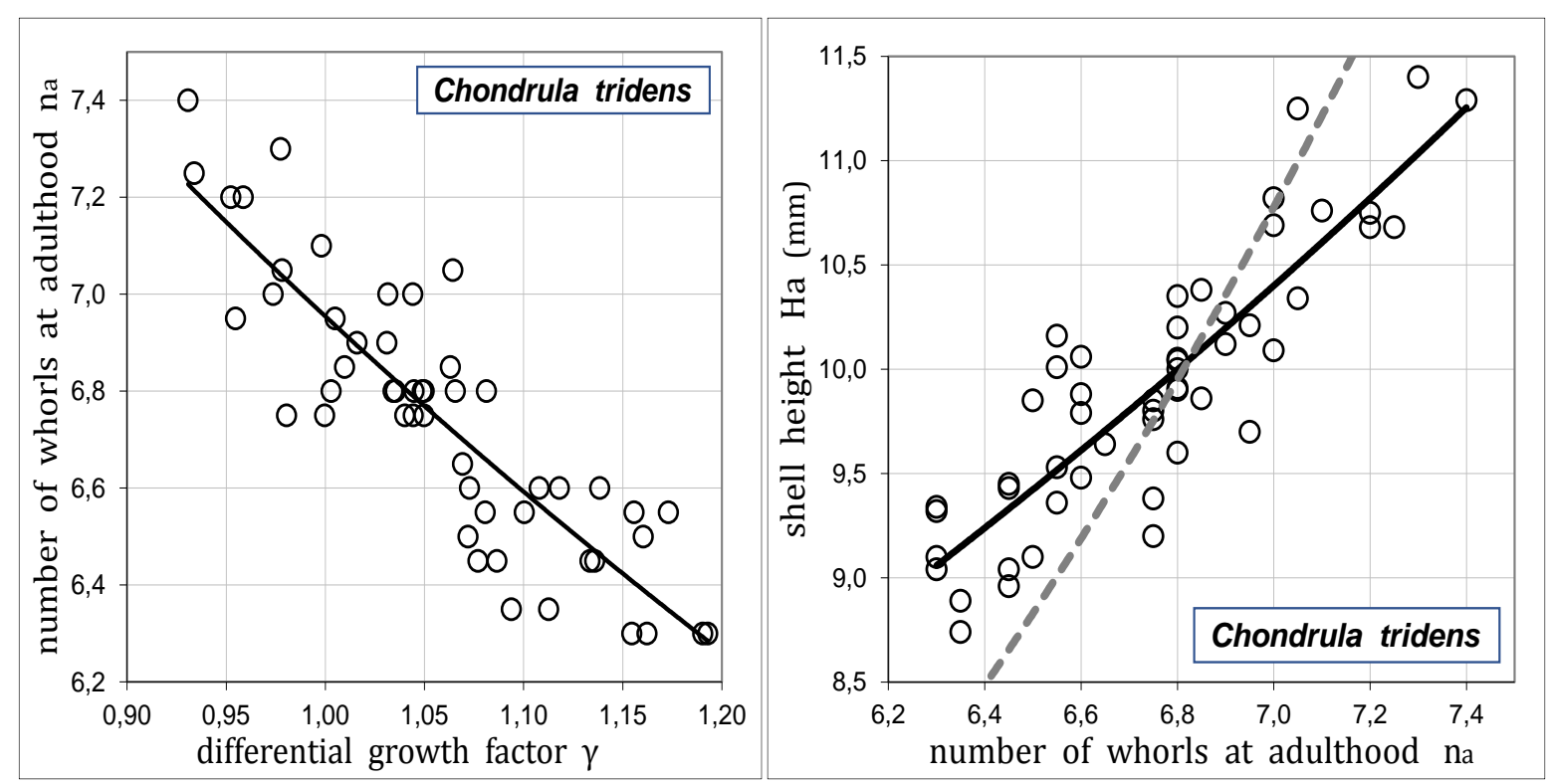

Figs. $11 \& 12$. Shell size regulation in a population of 51 individuals of the land snail Chondrula tridens. Left: negative covariance between the number of whorls at adulthood $n_{a}$ and the differential growth factor $Y(r=-0.87, p<0.0001)$, symptomatic of the resulting regulation of shell size. Right: shell height plotted against the number of whorls $n_{a}$; the slope of the regression (solid line) turns out to be 2.00 times lower than it would be if no regulation of the shell size had actually occurred (dashed line): $t=12.5$, d.d. $I=49, p<0.0001$.
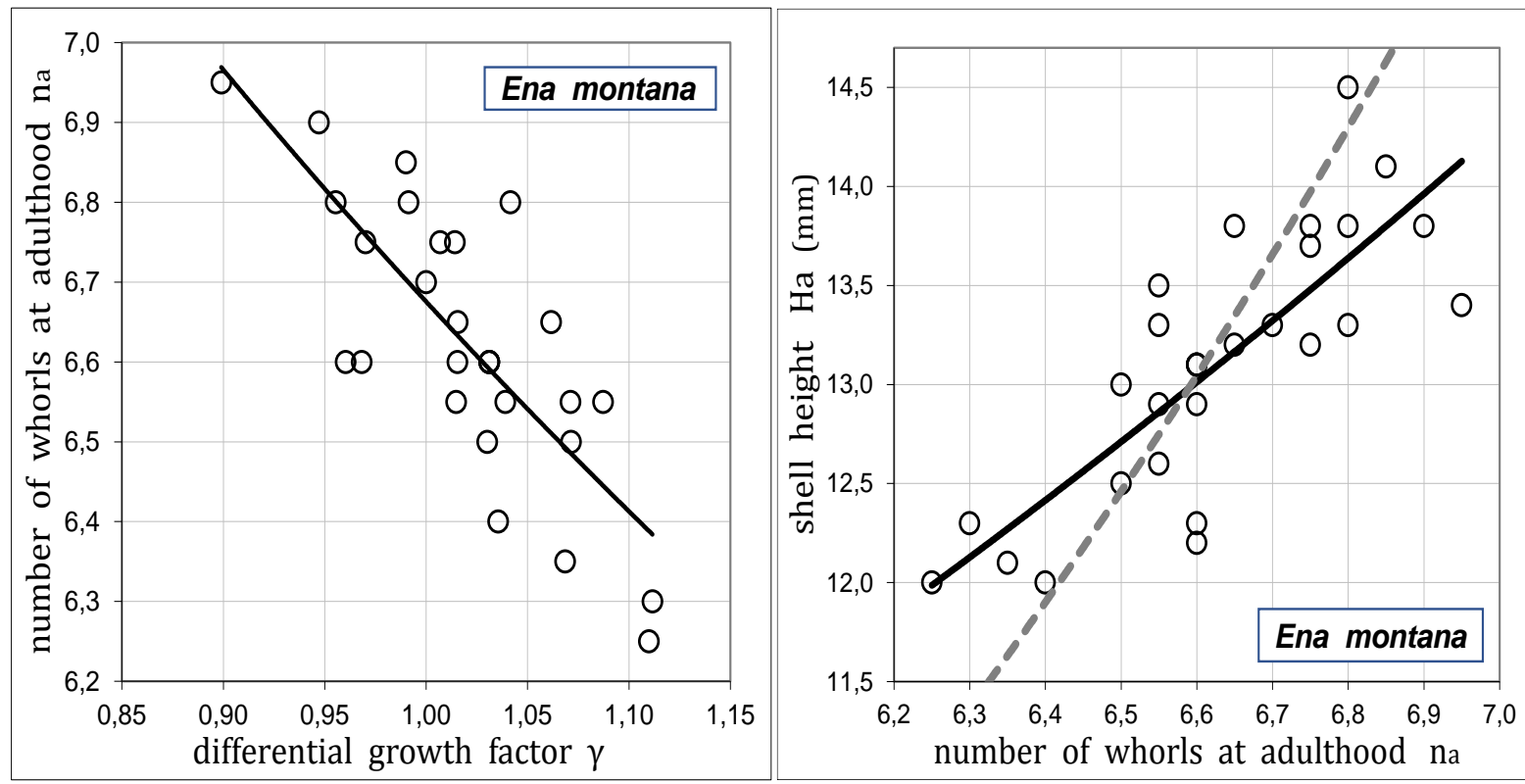

Figs. 13 \& 14 . Shell size regulation in a population of 28 individuals of the land snail Ena montana. Left: negative covariance between the number of whorls at adulthood $\mathrm{n}_{\mathrm{a}}$ and the differential growth factor $Y(r=-0.79, p<0.0001)$, symptomatic of the resulting regulation of shell size. Right: shell height plotted against the number of whorls $\mathrm{n}_{\mathrm{a}}$; the slope of the regression (solid line) turns out to be 1.97 times lower than it would be if no regulation of the shell size had actually occurred (dashed line): $t=6.5$, d.d.I $=26, p<0.0001$. 

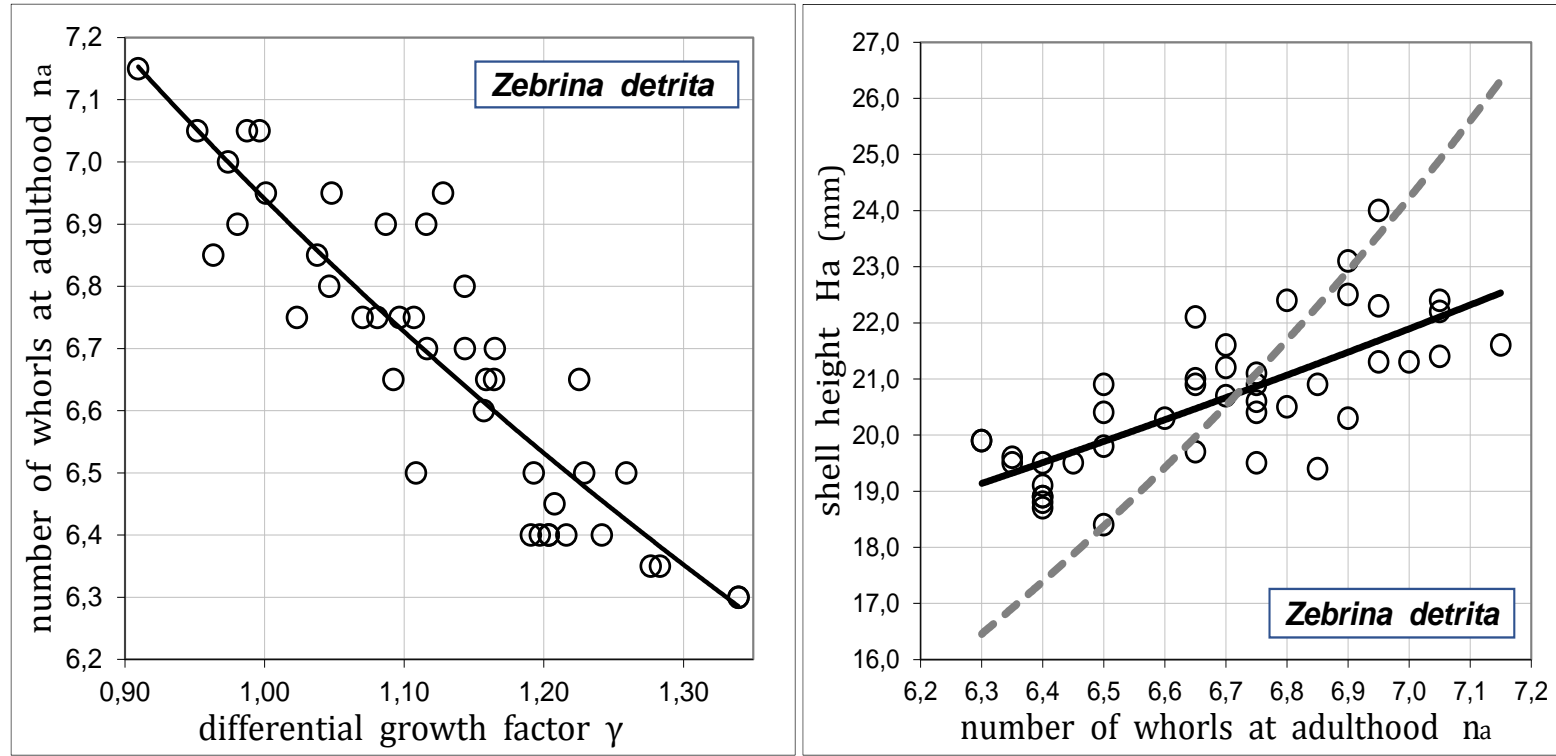

Figs. $15 \& 16$. Shell size regulation in a population of 43 individuals of the land snail Zebrina detrita. Left: negative covariance between the number of whorls at adulthood $n_{a}$ and the differential growth factor $y(r=-0.90, p<0.0001)$, symptomatic of the resulting regulation of shell size. Right: shell height plotted against the number of whorls $\mathrm{n}_{\mathrm{a}}$; the slope of the regression (solid line) turns out to be 2.85 times lower than it would be if no regulation of the shell size had actually occurred (dashed line): $t=12.8$, d.d.I $=41, p<0.0001$.

\section{DISCUSSION}

Body size is, perhaps, the most straightforwardly apparent characteristic of an organism [10]. And, for those species with determinate growth, as is the case for many land snail species, this stands more particularly for the adult body size and, by extension, stands as well for the shell size reached at adulthood (i.e., the size of "fully blown" shell). Generally speaking, for species with determinate growth, the adult body size is regulated by mechanisms that both control: (i) the rate of growth and (ii) the duration of growth [11].

Now, as regards fully grown conispirally-coiled shells, having reach the adult stage, it goes natural (and it is far more convenient in practice) to reformulate the preceding assertion as: 'the size reached by adult conispirally-coiled shells, is regulated by mechanisms that both control: (i) the whorls' growth parameter (here measured by the index $y$ ) and (ii) the number of whorls $\mathrm{n}_{\mathrm{a}}$.

And this, independently of whether or not the number of whorls $n_{a}$ indeed results of growth duration (as is often admitted but is, yet, unlikely to be always the case).

Still generally speaking, it is considered quite common, in studies of life-history plasticity, to find a negative relationship between the age of transition to adulthood and the growth conditions under which individuals are developing, with, in particular, higher growth rate typically resulting in earlier access to adulthood [12]. Accordingly, returning once again to conispirally-coiled shells, a negative covariance is expected to occur between whorls growth rate all along shell development and the number of whorls of fully blown shells. As already emphasized, such kind of negative covariance was highlighted in particular in the seminal reports by GoULD for the land snail genus Cerion. It seems logical to speculate that a same kind of negative covariance is to be encountered - more or less strong - in most, if not all, conispirally-coiled shells, among land snails. This seems, however, having been checked only in very few cases [6-8] as already mentioned. So that there is need to expand investigations to quite a larger range of land snail taxa - and this all the more that there may be some suspicion that the rule could possibly met some exceptions. For example, BAUR [13] reports that in the minute land snail species Chondrina clienta, the individuals of a given size all had the same whorl number, which would imply that either (i) no variability in growth rate actually takes place within populations of Chondrina clienta (which would seem rather unusual and unlikely) or, alternatively, that in 
fact, no negative covariance occurs between $y$ and $n_{a}$ in this particular species.

Hence, a still further incentive to investigate more widely and deeply on the subject. Which was the purpose of this preliminary contribution in this respect.

The eight investigated species studied above were therefore chosen as:

(i) covering a broad taxonomic spectrum (including one species of Prosobranchia, which are comparatively very few among land snails);

(ii) extended to the whole range of conispirallycoiled profiles, from globular, then discoid, up to more or less elongate shells, - thereby attempting to derive more general deductions;

(iii) corresponding to rather common species, in order to gain easier access to relatively numerous local populations of individuals, so as to identify statistically significant trends.

As regards the negative covariance between the differential growth index $y$ and the number of whorls $n_{a}$ at adult stage (considered as being symptomatic of the involvement of a regulation process controlling the adult soft-body size of land snails and thus resonating upon the regulation of fully blown shell size), highly statistically-significant confirmations of such involvement is obtained for each of all eight species $(p<0.0001$ in all cases).

However, if the indirect evidence has thus been provided of the implication of a regulatory process being operational in each of the eight species, it still remains to evaluate the degree of efficiency of this regulation, in terms of the degree of limitation of the range of variation of the adult shell size within a same population of a same given species. The reported results in Figs. $2,4,6,8,10,12,14$ and 18 show that the average slope of the regression of the adult shell size against the number of whorls is always markedly lower than would be expected in the absence of regulation. With, as a consequence, quite a narrower scatter of fully blown shell sizes than if no regulation had actually occur. The slopes, however, never fall to zero, that is to an ideally-perfect regulation. Thus, the regulation, however strong as it can be, yet remains only partial. But nonetheless rather significant since as compared to inoperative regulation - the slopes are reduced by a factor comprised between 1.75 (for Monacha cartusiana) and 24.3 (for Cornu aspersum) with an average factor of reduction of 5.53 (arithmetically) or 3.54 (geometrically, which is more relevant for a ratio). Thus, with an average trend for the shrinkage of the regression slope by more than a factor 3 , the efficiency of the regulation of the adult shell size in these eight investigated species proves being globally very determinant, although remaining not ideally perfect. Besides, reaching ideal perfection (i.e., the regression slope falling to zero) would not, in fact, so markedly improve the efficiency because the corresponding gain would be partly buffered by the unavoidable residual scatter of individual shell sizes at any given value of $n_{a}$, as apparent in all cases.

In addition, it seems that the efficiency of the regulation process might well be higher when combining both the shell height and the shell width (for example via the [computed shellvolume $]^{1 / 3}$ ), rather than by uniquely involving either the height or the diameter, as considered above (unpublished results with the land snails Pomatias elegans, Chondrula tridens and Ena montana). This, indeed, is not surprising but would nevertheless require further investigations.

Now - as efficient as shell-size regulation turns out to be - it yet remains that the level of regulation efficiency can differ very significantly, depending on species identity, as clearly exemplified when comparing the eight studied species with each other.

\section{CONCLUSION}

Beyond the demonstration of the likely systematic occurrence of an efficient regulation process constraining adult shell-size variations within species in land snails (which indeed was expected), it is the markedly species-specific character of the degree of efficiency of this regulation which features as the main lesson of the present study - as highlighted by the rather strong disparity between the degrees of regulation efficiency reported above among the eight studied species.

In addition, it turns out, also, that the types of profile of shells do not seem to be discriminant in this respect, contrary to what might have been hypothesized. Thus, the two species exhibiting respectively the higher and the lower degrees of regulation efficiency, Cornu aspersum and Monacha cartusiana, both belong, yet, to the same type of globular profiles, while the shells 
with discoid or more or less elongated profiles are in intermediate positions as regards the degrees of regulation efficiency.

\section{COMPETING INTERESTS}

Author has declared that no competing interests exist.

\section{REFERENCES}

1. Goodfriend GA. - Variation in land-snail shell form and size and its causes: $A$ review. Systematic Zoology. 1986; 35(2): 204-223.

2. Gould SJ. A developmental constraint in Cerion, with comments on the definition and interpretation of constraint in evolution. Evolution. 1989; 43(3):516-539.

3. Gould SJ, Paull C. Natural history of Cerion. VII. Geographic variation in Cerion (Mollusca: Pulmonata) from the eastern end of its range (Hispaniola to the Virgin Islands): coherent patterns and taxonomic simplification. Breviora. 1977;445:1-24.

4. Gould SJ, Woodruff DS. Systematics and levels of covariation in Cerion from the Turks and Caicos. Bulletin of the Museum of Comparative Zoology. 1987;151:321363.

5. Gould SJ, Woodruff DS. History as a cause of area effects: an illustration from Cerion on Great Inagua, Bahamas. Biological Journal of the Linnean Society. 1990; 40:67-98.

6. Béguinot J. Intra-specific variability of the growth rate of the shell and stabilizing regulation of adult size in gastropods: dedicated investigation tool and example of use. Bulletin Société d'Histoire Naturelle d'Autun. 2013; 205:29-40.

7. Béguinot J. - Regulation of the dimensional development of the shell in three species of Gastropods. Bulletin of the Linnean Society of Lyon. 2014; 83(5-6):119126.

8. Béguinot J. Stabilization of adult shell size despite the variability of growth, in a marine gastropod, the Common Natice,
Euspira catena. Bulletin Société Linnéenne de Bordeaux. 2014; 42(2):239-248.

9. Kerney MP, Cameron RAD. Land Snails of Britain and North-West Europe. Collins \& Sons Publishers, London; 1979.

10. LaBarbera M. Analyzing body size as a factor in ecology and evolution. Annual Review of Ecology and Systematics. 1989; 20:97-117.

11. Shingleton AW. Evolution and the regulation of growth and body size. in Flatt $T$ \& Heyland A. - Mechanisms of Life History Evolution: The Genetics and Physiology of Life History Traits and Trade-Offs. Oxford Scholarship Online; 2013.

12. Day T, Rowe L. Developmental thresholds and the evolution of reaction norms for age and size at life-history transitions. The American Naturalist. 2002;159(4):338-350.

13. Baur B. Microgeographical variation in shell size of the land snail Chondrina clienta. Biological Journal of the Linnean Society. 1988; 35:247-259.

14. Raup DM. The geometry of coiling in gastropods. Proceedings of the National Academy of Science USA. 1961;47:602609.

15. Raup DM. Geometric analysis of shell coiling: general problems. Journal of Paleontology. 1966; 40(5):1178-1190.

16. Acckerly SC. Shell coiling in Gastropods: analysis by stereographic projection. Palaios. 1989; 4:374-378.

17. Hutchinson JMC. Control of gastropod shell shape; the role of the preceding whorl. Journal of theoretical Biology. 1989; 140:431-444.

18. Hutchinson JMC. Control of gastropod shell form via apertural growth rate. Journal of Morphology. 1990;206:259-264.

19. Rice $\mathrm{SH}$. The bio-geometry of mollusc shells. Paleobiology. 1998;24(1):133-149.

20. Van Osselaer C, Grosjean P. Suture and location of the coiling axis in gastropod shells. Paleobiology. 2000;26(2):238-257.

21. Clements R, Liew TS, Vermeulen JJ \& Schilthuizen M. Further twists in gastropod shell evolution. Biology Letters. 2008; 4 : 179-182. 


\section{APPENDIX}

Disentangling and quantifying the respective contributions of growth parameters ' $n a$ ' and ' $y$ ' to the overall shell-size in conispirally-coiled shells

For those gastropod species with shell coiling geometry fairly approaching a conispiral profile and approximately answering the ideal exponential growth model (i.e. logarithmic spiral coiling), the contribution, $\delta_{i}$, of whorl number ' $i$ ' to the overall shell dimensions $\Delta$ (shell height or shell width) is, according to [14-21]:

$\Delta \mathrm{i}=\delta_{1} \cdot \varepsilon^{(\mathrm{i}-1)}$

where:

- $\delta_{1}$ is the contribution of whorl number one;

- $\varepsilon$ is the rate of whorl expansion (and, as well, the ratio between the contributions of two successive whorls: $\left.\varepsilon=\delta_{i+1} / \delta_{i}\right)$.

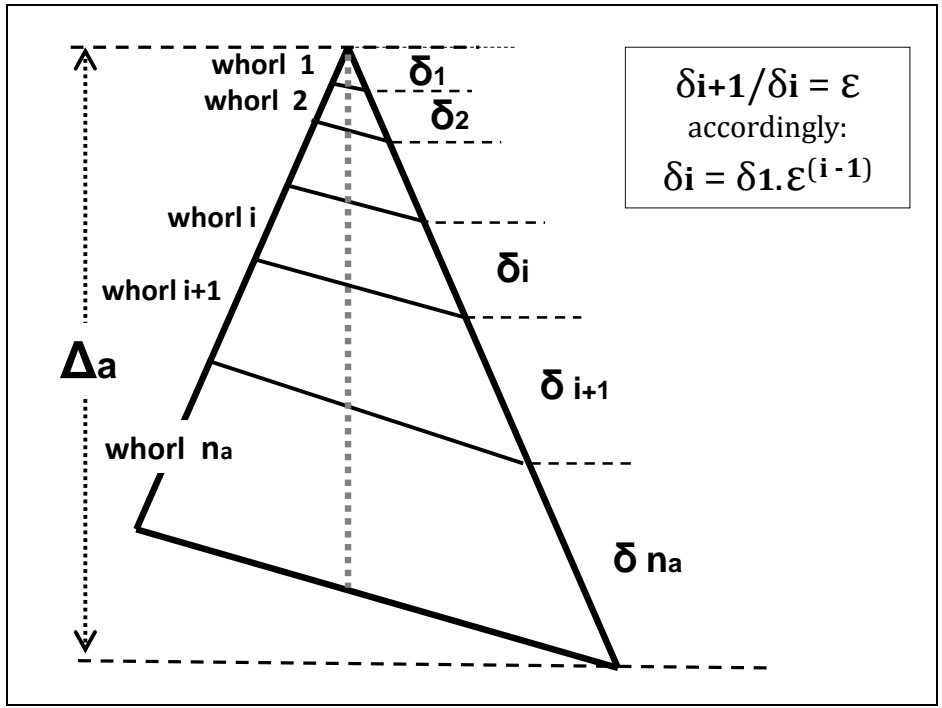

Fig. A1. Schematic sketch of the section of an ideally conispirally coiled shell, showing the morphometric parameters involved in this study: $n_{a}$ the number of whorls at adult stage; $\delta_{i}$ the contribution to shell-height of the $\mathrm{i}^{\text {th }}$ whorl; $\varepsilon$ the ratio of expansion of whorl section per revolution; $\Delta_{\mathrm{a}}$ the final, adult shell size. Here, for an elongated shell shape, the overall shell size $\Delta_{a}$ is identified to shell height. While, a globular or discoidal shell shape would answer a similar schematic sketch with, accordingly, the overall shell size taken as the shell diameter.

Then, for a shell with $\mathrm{n}$ whorls, the shell size is the sum of these $\mathrm{n}$ successive contributions:

$\Delta(\mathrm{n})=\sum_{\mathrm{i}=1}$ to $\mathrm{n}\left(\delta_{\mathrm{i}}\right)=\sum_{\mathrm{i}=1}$ to $\mathrm{n}\left(\delta_{1} \cdot \varepsilon^{(\mathrm{i}-1)}\right)=\left[\delta_{1} /(\varepsilon-1)\right] \cdot\left(\varepsilon^{\mathrm{n}}-1\right)$

$\Delta(\mathrm{n})=\mathrm{c} .\left(\varepsilon^{\mathrm{n}}-1\right)$

with $\Sigma_{i=1}$ to $n$ designing the summation extended to the $n$ whorls of the shell and $c=\left[\delta_{1} /(\varepsilon-1)\right]$

The size of a shell having reached its adult stage, with a corresponding number $n_{a}$ of whorls, is thus $\Delta_{a}\left(=\Delta\left(n_{a}\right)\right)$ defined as follows:

$\Delta_{\mathrm{a}}=\mathrm{c} .\left(\varepsilon^{\mathrm{na}}-1\right)=\left[\delta_{1} /(\varepsilon-1)\right] \cdot\left(\varepsilon^{\mathrm{na}}-1\right)$ 
Some more or less limited discrepancies may exist, of course, between the specific reality and the idealised, classical conispiral model involving whorls contributions regularly increasing exponentially with the whorl numbering label. Yet, here, focus is placed on the inter-individual variability and we are dealing with variations of shell size rather than with the estimates of size itself. As first order discrepancy regarding the absolute values taken by a parameter have only second-order influence upon the inter-individual variations of this parameter, it follows that using the idealised classical model remains appropriate to the subject under study here.

\section{Defining a synthetic parameter ' $\gamma$ ' accounting for the combined contributions of growth parameters $\delta_{1}$ and $\varepsilon$}

The parameters $\delta_{1}$ and $\varepsilon$ govern together the geometry of progressive shell development (equation A2). Either or both parameters are subjected to intra-specific (i.e. inter-individual) variability, inducing in turn, an inter-individual variability of the shell size reached at any given number of whorls. As for any other phenotypic character, the intra-specific variability of shell growth parameters may conveniently be considered by reference to a conventionally defined "type specimen" (characterised by the referential values $\delta_{1}{ }^{*}$ and $\varepsilon^{*}$ of parameters $\delta_{1}$ and $\varepsilon$ respectively, for the species under consideration).

The consequence on the adult-shell size of the intra-specific variability of growth parameters $\delta_{1}$ and/or $\varepsilon$ may then be quantified by the variations of the ratio:

$Y=\Delta_{a} / \Delta_{a}^{*}$

where:

- $\Delta_{\mathrm{a}}$ is the adult size of the shell under consideration;

- $\Delta_{\mathrm{a}}{ }^{*}$ is the size that the type specimen (or any specimen having the same parameters $\delta_{1}{ }^{*}$ and $\varepsilon^{*}$ ) would take for a number of whorls equal to the number of whorls $n_{a}$ of the adult-shell under consideration. The value of $\Delta_{a}{ }^{*}$ is provided by equation (A2) with $\delta_{1}=\delta_{1}{ }^{*}$ and $\varepsilon=\varepsilon^{*}$ :

$\Delta_{a}^{*}=c^{*} \cdot\left(\varepsilon^{* n a}-1\right)$, with $c^{*}=\delta_{1}^{*} /\left(\varepsilon^{*}-1\right)$

Thus defined, the parameter $y$ integrates the influence of $\delta_{1}$ and $\varepsilon$ on the geometrical development of the shell all along its ontogeny (via $\varepsilon$ ) and since its very beginning (via $\left.\delta_{1}\right)$. Parameter y may thus be designed as "individual growth factor" or, focussing here upon the intra-specific variability, as "differential growth factor". Although there is, of course, no possibility of disentangling the respective contributions to $\gamma$ of parameters $\delta_{1}$ and $\varepsilon$, it remains that $\gamma$ conveniently accounts for the combined contributions of $\delta_{1}$ and $\varepsilon$ to the overall shell size $\Delta$, at any given value of the number of whorls, by reference to a freely chosen type specimen of the corresponding species.

\section{A.3 - Practical procedure}

Consider a population of adult individuals (belonging to a same species having been previously typified with a referential "type specimen", in terms of the values of $\delta_{1}{ }^{*}$ and $\varepsilon^{*}$ ) submitted to a morphometric study. For each individual, both the number of whorls $n_{a}$ and the shell size $\Delta_{a}$ are measured, the later by using a numeric calliper and the former by careful examination from shell apex (according to procedure by KERNEY \& CAMERON [9] under stereo-microscope at moderate magnification, typically allowing a precision at a level of 1/10 whorl revolution. Now, introducing the measured values $\delta_{1}{ }^{*}$ and $\varepsilon^{*}$ in equation (A4) provides the value of $\Delta_{a}{ }^{*}$. Then, introducing the measured value of $\Delta_{a}$ in equation (A3) provides the values of the differential growth index $y$ for each of the individual shells under study. Thus, the growth components $n_{a}$ and $y$ (that have together determined the adult shell size $\Delta_{a}$ ) are thus conveniently and easily made available for each member individual of the population under study. 
We thus dispose of a tool to give a more "quantitative turn" to the adage by GoULD, already quoted in Introduction: that is, conispirally-coiled Gastropods "may reach larger size either by growing more whorls (i.e. by growing larger $\boldsymbol{n}_{\mathbf{a}}$ ) or by growing larger whorls (i.e. by exhibiting larger $\boldsymbol{Y}$ )".

(c) 2021 Béguinot; This is an Open Access article distributed under the terms of the Creative Commons Attribution License (http://creativecommons.org/licenses/by/4.0), which permits unrestricted use, distribution, and reproduction in any medium, provided the original work is properly cited.

Peer-review history:

The peer review history for this paper can be accessed here: https://www.sdiarticle4.com/review-history/75437 